\title{
Atlas para um paraíso privado ou A sagração da Primavera do século XXI
}

\section{Alexandra Balona}

Titulo: Paraíso - Colecção privada. Coreografia: Marlene Monteiro Freitas. Intérpretes: Yair Barelli, Lorenzo De Angelis, Luis Guerra, Andreas Merk, Marlene Monteiro Freitas. Música: Nosfell. Luz: Yannick Fouassier. Figurinos. Marlene Monteiro Freitas. Produção e difusão: Andreia Carneiro (Bomba Suicida, Lisboa, PT), Erell Melscoet (FR). Co-produção: Les Spectacles Vivants, Centre Pompidou (FR), L'Échangeur, CDC Picardie (FR), CCN de Tours (FR), CCN de Rillieux-la-Pape (FR), Ballet National de Marseille, CCN (FR), CDC Uzès Danse (FR), Bomba Suicida (PT), Festival Circular, Vila do Conde (PT), Maria Matos Teatro Municipal (PT). Local e data de apresentação: Montemor-o-Novo, PT.13 - plataforma portuguesa de artes performativas, 29 de Maio 2013.

Toda a tragédia humana de Prometeu se resume nestes termos: não existe uma abóbada fixa sobre nós Porém, temos de usar esta imagem elevada para proporcionar uma construção auxiliar, ainda que arbitrária aos nossos olhos perplexos perante a infinidade. Aby Warburg (2010: 16)

Nas profundezas obscuras da mente [e do corpo] - aqui, a caixa negra do palco - pousa uma estrutura de varas metálicas, pontuada com luzes quentes e sulfurosas, de organização-desorganizada, onde se avistam seres estranhos, ao som de um intrigante chilrear de pássaros.

Espaço dentro de um espaço, matrioshka para o lugar dos sonhos, da imaginação ou do inconsciente, esta "espécie de gaiola suspensa", nas palavras de Marlene Monteiro Freitas "que, por um lado, desafia a gravidade e, por outro lado, tem paredes móveis e transponíveis, guarda seres com asas": os seres hibridos e desconcertantes da imaginação, as aves e os anjos do Paraíso, os phantasmas da fantasia.

Este é o lugar "heterotópico" (Foucault 1966: 9) da peça Paraíso - Colecção privada, o paraíso inventado dos artistas e dos poetas e, neste caso preciso, da coreógrafa e intérprete Marlene Monteiro Freitas e dos intérpretes Yair Barelli, Lorenzo de Angelis, Luis Guerra e Andreas Merk que, tendo estreado no Circular - Festival de Artes Performativas, em Vila do Conde, em 2012, foi apresentado em Lisboa, no Teatro Municipal Maria Matos e na IP13 em Montemor-o-Novo, em 2013, e continua em circulação por diversas salas e festivais internacionais.

Para este Paraiso imaginário - território de liberdade - confluem matérias heterogéneas e contraditórias que, segundo a coreógrafa, "activadas por dinâmicas opostas de repressão e desejo" fecundam imagens e gestos insólitos, desmoronando qualquer plano epistémico coerente e lógico que o público possa expectar.

E é este concerto coreográfico que se pretende propor aqui como sendo já uma peça singular do início deste século XXI, atrevendo a comparação, em certos aspectos, com Le sacre du printemps. Tableaux de la Russie païenne en deux parties pelos Ballets Russes, que estreou no Théâtre des Champs-Élysées, em Paris, a 29 de Maio de 1913.

0 que estimula este indício de proximidade não será tanto a especificidade da composição musical ou da coreografia, nem tão pouco o conteúdo semântico, mas a intuição de que ambas as peças são, em certa medida, uma resposta-diagnóstico ao seu tempo e recorrem a influências mitológicas e pagãs para elaborar sobre a própria condição humana, tendo provocado no público, no caso de Le sacre du printemps, a turbulência já lendária e, no caso de Paraíso - Colecção privada, um estranhamento aliado a um certo fascinio, como se constata pela imprensa nacional e internacional ${ }^{2}$. A peça, partindo de Le sacre du printemps

[...] ficciona um ritual arcaico - o sacrificio de uma jovem, escolhida entre diversas outras, que dança até à morte em prol da bênção do Sol e do deus da fertilidade Yarilo - e baseia-se na iconografia e literatura da mitologia primitiva eslava, que estará na base do paganismo formador da cultura russa, e de que Nicholas Roerich (etnógrafo e artista, assinou a cenografia, os figurinos e o libreto da peça) era um profundo conhecedor. (Brandstetter 1998: 38)

A partitura musical de Stravinsky, cunhada pelos sons e ritmos dos cantares tradicionais russos, resultou numa composição revolucionária, de ritmo sincopado, com transições abruptas e dissonantes, e de uma intensidade tribal e electrizante.

Quanto à criação coreográfica, Vaslav Nijinsky, que tinha já evidenciado a sua genialidade em L'après-midi d'un faune (1912), pela irreverência com que a peça
Todas as citações da coreógrafa têm como fonte a Entrevista a Marlene Monteiro Freitas que efectuei por correio electrónico no dia 23 de Outubro de 2013 (inédita).

${ }^{2}$ Veja-se o respectivo dossiê no sitio: http://cargocollective.co $\mathrm{m} /$ marlenefreitas/p-a-ra-i-s-o.

Alexandra Balona é licenciada em Arquitectura pela Faculdade de Arquitectura da Universidade do Porto e, como bolseira da FCT, prepara uma tese no âmbito do Programa Media and Communications da European Graduate School. 


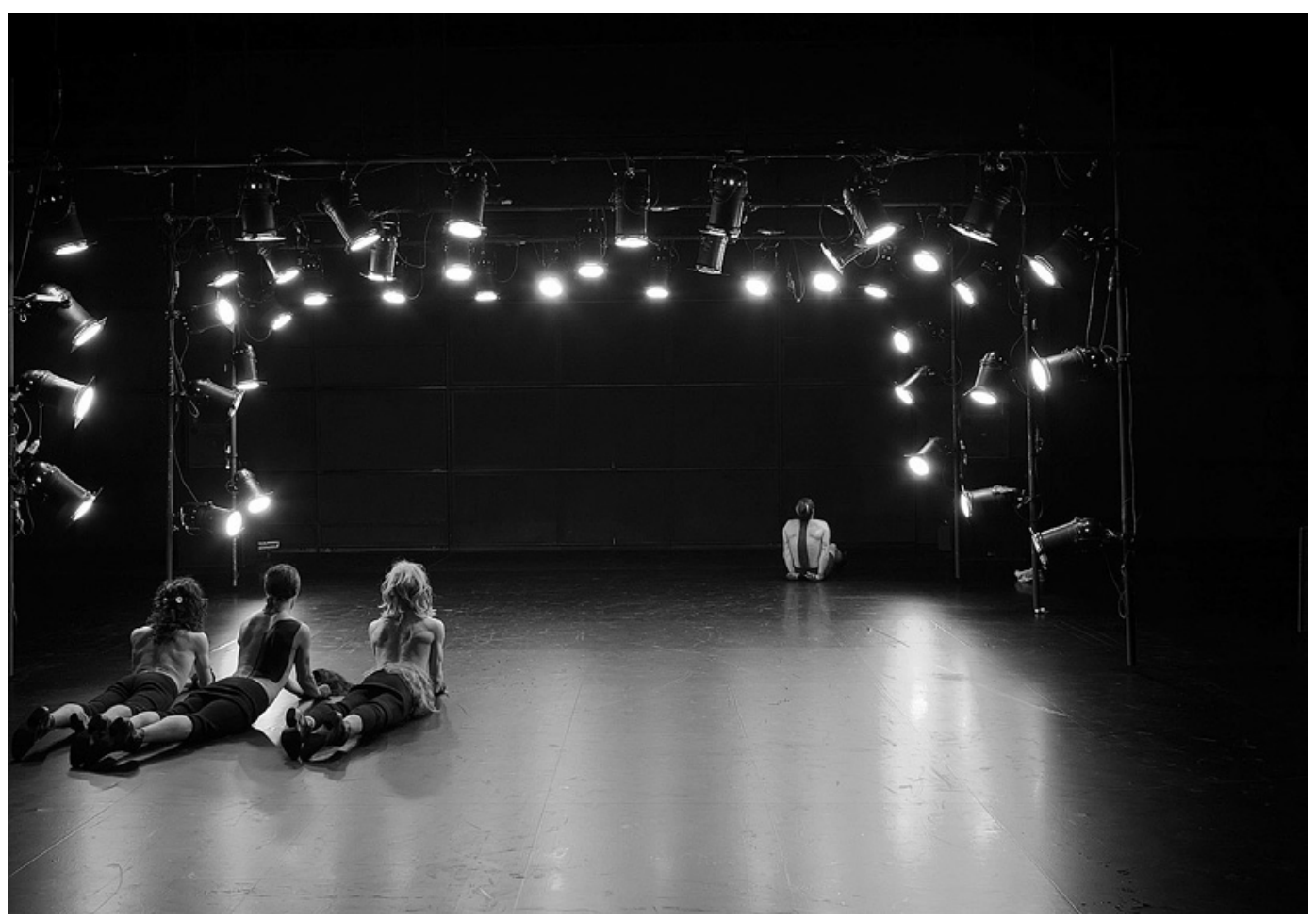

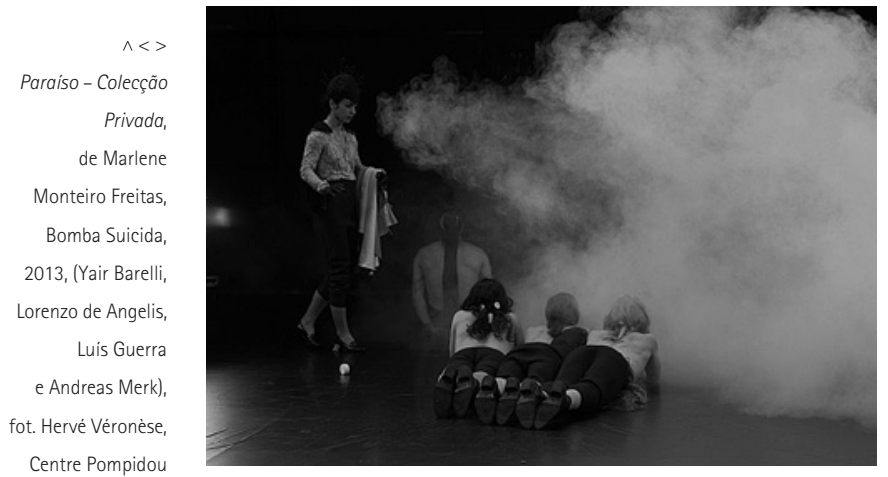

Centre Pompidou (Cortesia Marlene Monteiro Freitas).

incorpora traços do paganismo grego e egípcio, "numa animalidade semi-consciente" (Reiss 1958: 135), em busca de um retorno a uma experiência originária perdida, prossegue em Le sacre du printemps com a desconcertante proposta onde, uma vez mais, se rompem os cânones do ballet clássico, em termos estéticos, semânticos, iconográficos e espaciais. A simetria e o centro ideal são abolidos, a atenção dissemina-se em cada intérprete que em si mesmo, se converte num veículo individual de expressão da música e das emoções. A gramática de movimentos centra-se no andar, correr e saltar. Os gestos perdem a graciosidade das curvas, a elegância e a leveza artificial do clássico, para se enraizarem na terra: corpos com o torso contraído, pés voltados para dentro, pernas semi-flectidas, saltos bruscos e repetições obsessivas, que reiteram o carácter extático das danças arcaicas.

Nijinsky cria esta peça para os Ballets Russes de Diaghilev, no contexto de um modernismo que, em torno de 1900, sob o signo da ambivalência e do relativismo, se definia por uma experiência de crise (crise de percepção, de representação e de valores) e "pelo confronto de tempos contraditórios: o tempo objectivado da ciência moderna do capitalismo, da industrialização, versus o tempo pessoal subjectivo, ou a durée do imaginário" (Calinescu 1987: 5).

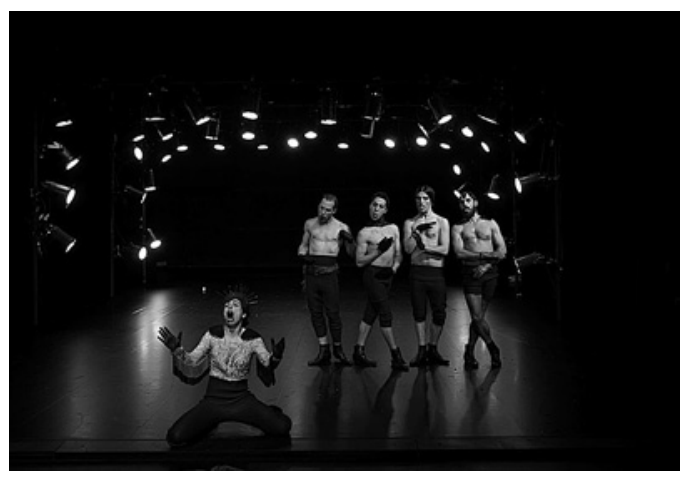

A "influência reciproca entre a arte e as ciências, tais como a antropologia, a etnografia, ou a psicanálise, contribuíram para desvelar o outro primitivo, e para o confronto dai resultante com a cultura ocidental" (Brandstetter 1998: 38). Ainda, assistia-se à afirmação de uma nova corporalidade que procurou resgatar na mitologia pagã da antiguidade, ou nas culturas exóticas, outra liberdade de relação entre os corpos, e destes com a natureza e o cosmos (Freikörperkultur alemã, François Delsarte, método Dalcroze, Loïe Füller, Isadora Duncan, Rudolph Laban, entre outros).

Neste sentido, Le sacre du printemps poderá ser visto como um momento sintomático desta fissura na autopercepção de um modernismo (em crise).

A peça Paraíso - Colecção privada, por oposição, não foi estruturada como uma narrativa de um ritual arcaico. Ainda assim, enquanto construção de um espaço onírico integra elementos não lógicos e pulsões inconscientes que, no dealbar do modernismo, seriam tidas como próximas de um paganismo primitivo, à semelhança de Le sacre du printemps.

Tendo como enfoque o tema do paraíso, icónico na génese da religião judaico-cristã, seminal para a compreensão da civilização europeia e dos valores que 

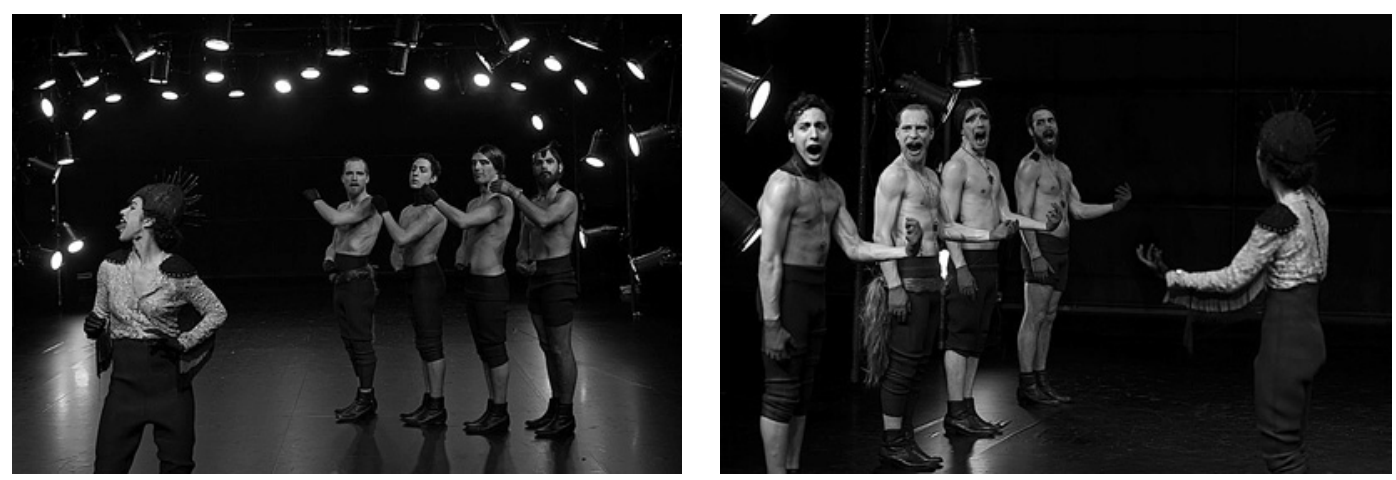

$<>\mathrm{V}<\mathrm{v}>$

Paraiso - Colecção

Privada, de Marlene

Monteiro Freitas, Bomba

Suicida, 2013

(< Marlene Monteiro

Freitas, Andreas Merk,

Lorenzo de Angelis, Luis Guerra e Yair Barelli;

$>$ Lorenzo de Angelis,

Andreas Merk,

Luis Guerra, Yair Barelli
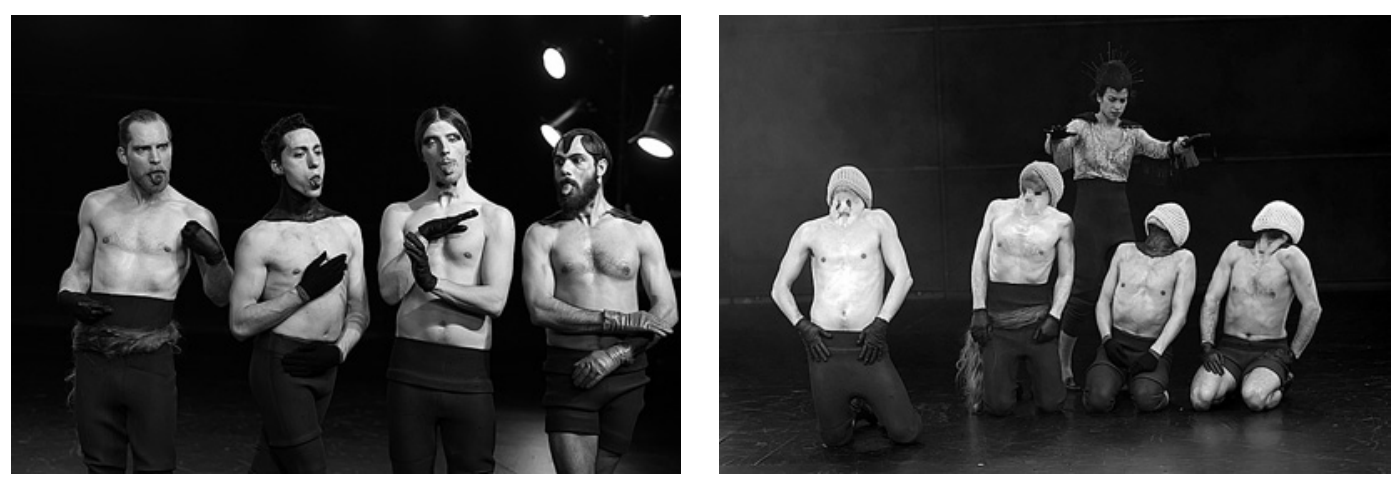

e Marlene Monteiro

Freitas;

$\mathrm{v}<$ Andreas Merk, Lorenzo de Angelis, Luis Guerra e Yair Barelli;

v> Luis Guerra, Andreas Merk, Marlene Monteiro Freitas, Lorenzo de Angelis e Yair Barelli), fot. Hervé Véronèse, Centre Pompidou (Cortesia Marlene Monteiro Freitas).

ainda hoje nos cunham, esta peça parte de uma montagem heterogénea de elementos bizarros e ininteligiveis para criar o seu paraíso inventado. Assim, no palco infiltramse vestígios visionários dos artistas e poetas, gestos e "imagens migratórias" ${ }^{3}$ da iconografia religiosa, nomeadamente, do Inferno de Torcello, do Jardim das delícias terrenas de Hieronymus Bosch, dos jardins de Cranach e Van Eyck, do mito de Adão e de Eva, assim como sonoridades eclesiásticas de Messiaen.

De ordem pagã surgem ainda pontos de contacto, segundo Marlene, "com o grotesco e o tornar-se outrem do Carnaval" (neste caso, de Cabo Verde, de onde é originária a coreógrafa), ou com as sonoridades e os ritmos viscerais do Kuduro e da Batucada.

Do legado cinematográfico, além de Les maîtres fous de Jean Rouch, basilar para a obra da autora ${ }^{4}$, outras influências permearam esta peça, como o filme surrealista Le chien andalou, de Salvador Dali e Louis Buñuel, o Enfer de Clouzot, ou o Yellow Submarine dos Beatles.

Todavia, à estranheza desta montagem híbrida de apropriações e invenções, que intitulamos aqui de "Atlas para um paraíso privado", subjaz algo de paradoxalmente familiar, como se, por intuição ou empatia, do desconcertante da peça se extraíssem indícios reconheciveis.

Mas, regressemos, então, ao lugar do Paraíso. Docemente entra a ária barroca "Ombra mai fu", da ópera Xerxes de Haendel, e os quatro intérpretes em cena permanecem imóveis, sob o olhar quente dos focos suspensos: quatro seres de génese híbrida, em tronco nu, calças escuras de neoprene e perucas na cabeça, três deitados de face no solo e um sentado ao fundo da cena.

0 órgão de Olivier Messiaen, denso e angustiante, precipita o estremecimento dos corpos que, na horizontal, agitam o pélvis numa cadência animalesca, enquanto que o ser sentado saltita com a cautela do animal que cobiça a presa.
Uma figura bizarra faz a sua entrada - a mulhertoureira, mágica-demiurgo - que, com rasgada expressividade no rosto e nas mãos, conduz os quatro seres, ordena-Ihes as posturas e os movimentos, do mesmo modo com que dá indicações à régie para cortar ou repor o som, aumentar ou reduzir o volume. É Marlene Monteiro Freitas, a maestrina do seu concerto coreográfico.

Os quatro seres, colocados em linha e de frente para o público, desenham movimentos rectos e nervosos com a cabeça, os braços e as mãos, reconhecendo-se nas suas figuras e gestualidade reminiscências iconográficas, nomeadamente, do Inferno que figura no mosaico bizantino do Último julgamento (século XII-XIII), na catedral Santa Maria Assunta, em Torcello.

Marlene, a mulher-aranha, mágica e dominadora dos seus seres, aproxima-se da plateia e, em silêncio, ensaia truques de magia, poses e feições grotescas, como que testando o seu próprio reflexo num espelho imaginário. Segundo a coreógrafa:

[...] em muitos momentos da peça existe esse espelho mental entre os intérpretes e a coreógrafa, e entre estes e o público. Além de se tratar de um jogo narcisico (mas o narcisismo é um pecado capital...), é uma forma de conseguir uma presença 'fora de si' à força de se estar exageradamente consigo próprio. Por conseguinte, uma forma de geral intensidade, e de o fazer à parte, independentemente da música. (Freitas in Balona 2013)

Ao longo da peça, a natureza das criaturas permanecerá sempre incerta - seres heterogéneos e em contínua mutação, faunos, seres andróginos, marionetas, bonecos, homem-cavalo, homem-cão, homem-música, homemflamenco - bem como a sua relação múltipla com a criadora: de submissão, desejo, veneração ou cumplicidade.

A peça prossegue como um mosaico coreográfico de momentos insólitos, sempre conduzidos pela maestrina, e que combinam o desconcertante com o humor: dos
${ }^{3}$ Para Aby Warburg, e no âmbito do seu projecto Kulturwissenschaft, ou Ciência da Cultura, as imagens são veículos privilegiados para a mobilidade geográfica e cultural "cuja consideração torna cada estilo artistico e cada cultura nacional ... uma entidade essencialmente, hibrida, impura e múltipla" (Didi-Huberman 2010: 24).

4 Este é um segundo

momento de reflexão da autora sobre a obra desta coreógrafa. Para o primeiro momento e uma análise alargada sobre 0 percurso da mesma, ver: http://maiscritica.wordp ess.com/2012/10/07/par aiso-informe/. 
cento e seis

| Sinais de cena 20. $2013 \mid$

L'après-midi d'un faune, de Vaslav Nijinsky, Ballet Russes, 1912, fot. Walery

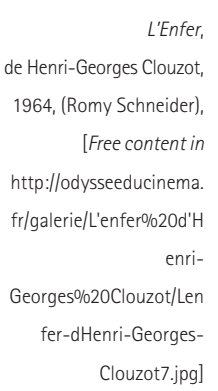$$
\text { Clouzot7.jpg }
$$

The Garden of Earthly Delights, Hieronymus Bosch, Madrid, Museu do Prado, 1480-1505, detalhe

[Free content in http://commons.wikime

dia.org/wiki/File: Bosch,_Hieronymus_-

The_Garden_of Earthly_Delights,_centra I_panel_-_Detail_duck_

feeding_man

(lower_left_side).jpg]

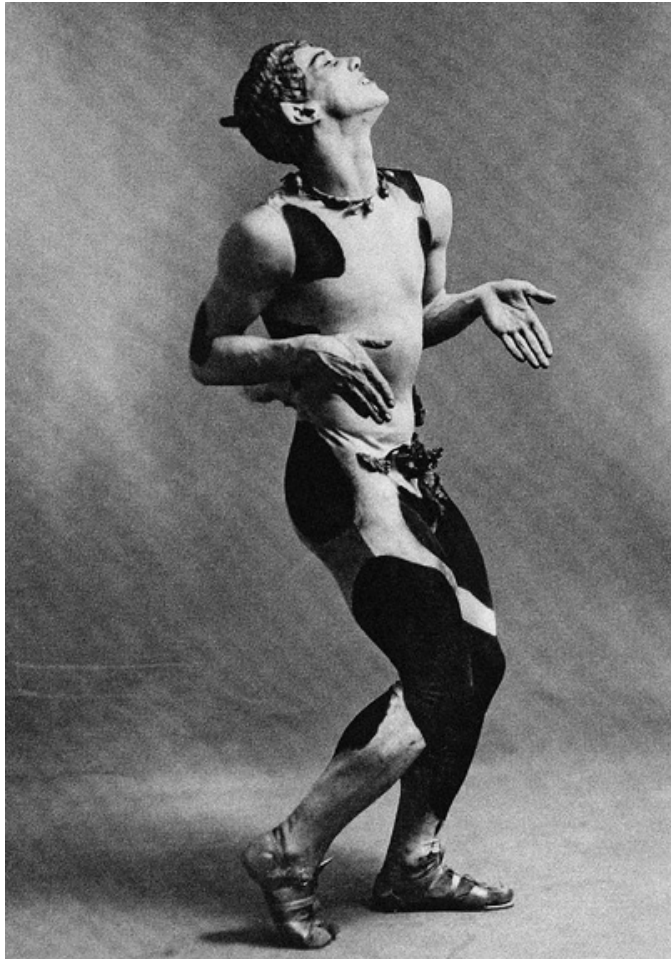

movimentos sensuais e cadenciados ao som do Kuduro, à introdução de objectos no interior da boca que deformam o rosto e produzem som, à electrizante performance do homem-cavalo que canta Psycho Killer dos Talking Heads, ao homem-cão e seus instintos mais primários, ao sermarioneta, ao solo do homem-pássaro, à insólita metamorfose dos intérpretes que, desvelando pinturas de um outro rosto no seu corpo, personificam outros seres e, uma vez mais, escapam a qualquer lógica e coerência.

A música, como a própria coreografia, é uma montagem hibrida conduzida por Marlene e que, nas suas palavras, "compreende interrupções, silêncios ou alterações de volume que induzem ora cortes de relação com o público, ora chamadas de atenção à cena". Atravessando obras de Messiaen, Haendel, Lully, Purcell, Wagner, Dj Leo Kuduro ou Talking Heads, a peça termina numa extática batucada final.

Ainda, na peça é conferida particular atenção a detalhes que, desestabilizando o imaginário dos intérpretes e do público, contribuem significativamente para o estranhamento geral. Refiro-me, nomeadamente, a elementos cuja polissemia as palavras da coreógrafa permitem aqui deslindar: as luvas que "nos tornam menos humanos"; a exploração da plasticidade da boca, da língua e dos olhos que "desorganizam a zona de verificação/ identificação" do rosto; os objectos inseridos na boca que apontam para "movimentos de entrada e saída do corpo" (ar, voz); as pinturas no corpo, que remetem para "tatuagens, corpo marcado, o universo dos cartoons, zonas escuras (buracos, ausência de matéria)"; os gestos das mãos, icónicos nas representações religiosas; o cuidado na escolha das cores e figurinos: as calças de neopreno (possivel leitura sadomasoquista) "criam um microclima [...], ajudam a produzir suor... a tinta espalha-se pelo corpo maior sujidade"; as cores fortes são reminiscentes das referências artísticas e religiosas: o preto ("buraco negro.. mistério, fertilidade"), o violeta/púrpura (do "majestoso",
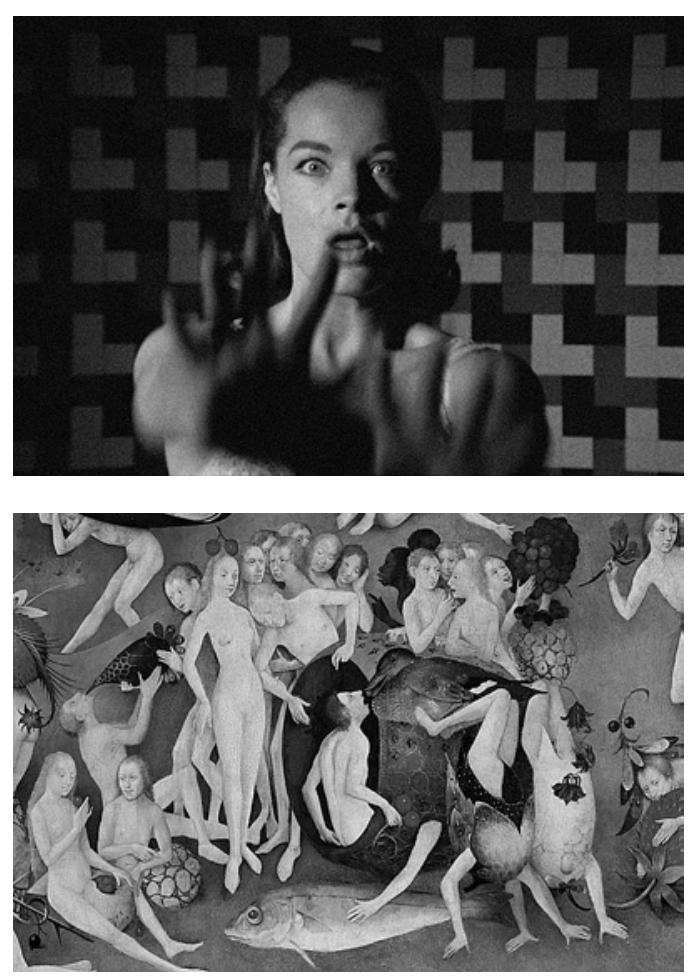

ao pagão, ao "religioso"), verde ("vigor, vegetal; morte... bolor, veneno... diabo, fertilidade"), amarelo ("luz/sol, envelhecimento, ouro... transição, diabo... colérico, deus, etc.").

Finalmente, no decorrer da peça, destaca-se um instante particularmente insólito: a coreógrafa dá sinal de intervalo aos intérpretes e à régie e, o público, sem aviso, assiste a esta pausa inesperada. Por momentos, os performers relaxam, Marlene transpõe os limites da estrutura cenográfica e, enquanto os intérpretes aguardam, fica sentada no palco mas fora do espaço cénico, come à mão uns pedaços de frango cozinhado. Este gesto desconcertante é só mais um acentuar da liberdade e arrojo que torna esta peça um objecto singular no contexto da criação contemporânea.

Retornando à peça Le sacre du printemps, a sua recepção terá sido tumultuosa não só porque esta rompeu com os cânones do ballet clássico, mas porque penetrou no universo mitológico da génese pagã da cultura russa de onde resgatou, por meio de um ritual, aquilo que seriam traços identitários de um povo (não sem uma componente de afirmação política e nacionalista), mas que foram expostos em palco através de corpos e gestos instintivos e primários. E terão sido estes corpos e gestos, não muito distantes de uma animalidade que, aliás, também nos conforma enquanto humanos, os agentes da perturbação na estreia da peça, em 1913. (Não existe registo de imagens em movimento da peça original, logo, estas reflexões baseiam-se na recriação de Millicent Hodson e Kenneth Archer, pelo Joffrey Ballet, em 1987).

Tanto em Le sacre du printemps, como na peça Paraíso - Colecção privada, uma força basilar impregnou a atmosfera geral, algo que eu arriscaria comparar ao que Aby Warburg cunhou de vida-póstuma (Nachleben), ou "saber sobrevivente", da cultura pagã. Em ambas as peças, uma tremenda carga energética armazenada nos gestos na música e nas imagens (vivas) infiltrou-se no público, instigando vibrações de ordem emocional e instintiva, 


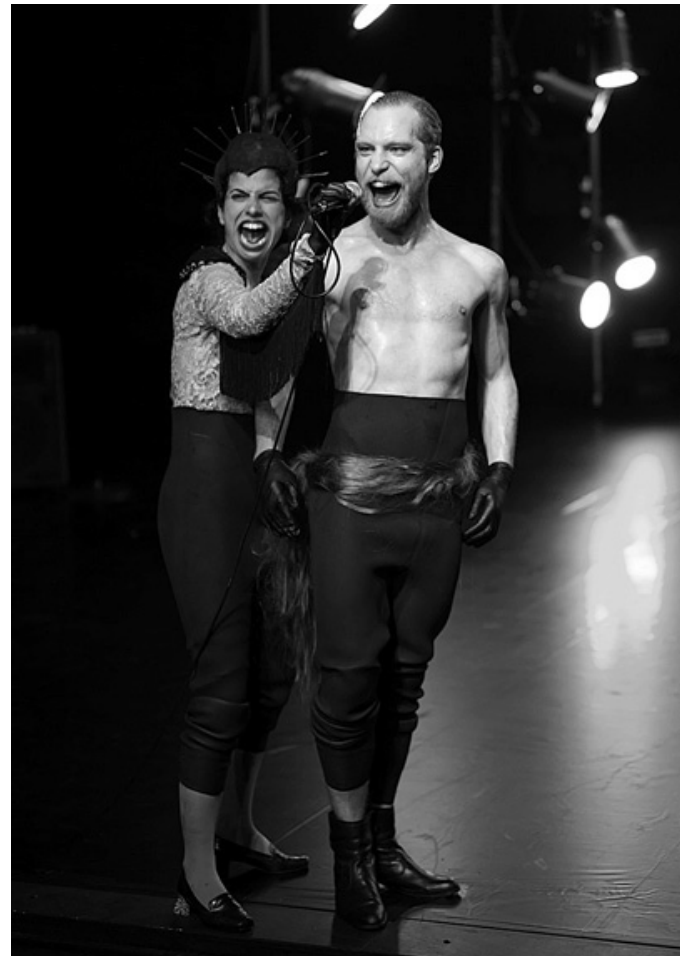

sem que estas pudessem ser verdadeiramente processadas em termos racionais. Algo reconhecivel por incorporação, porém, inefável.

Para Warburg, os símbolos e as imagens são a "cristalização de uma carga energética e uma experiência emocional que sobreviveu como uma herança transmitida pela memória social e que, [...] enquanto dynamogramas são transmitidos aos artistas em estado de grande tensão", cabendo a estes últimos polarizar esta energia recebida, infiltrar e depurar estas imagens, ou "engramas" das tensões espirituais de uma cultura, nas suas próprias obras (Agamben 1999: 94).

Warburg dedicou os últimos anos da sua vida à montagem orgânica de um atlas de imagens, projecto que chamou de Atlas Mnemosyne e que, segundo o próprio, seria "uma espécie de condensador que reuniria todas as correntes energéticas que animaram e continuariam a animar a memória da Europa, baseando-se nos seus fantasmas" (ibid.: 95).

Por conseguinte, poder-se-ia encontrar nesta peça a possibilidade de um "Atlas de imagens (vivas)", ou seja, não de imagens fixas, mas gestos e corpos em movimento. Neste sentido, Paraíso - Colecção privada apresenta esse carácter de diagnóstico (irónico) de um tempo que, sendo de agora, encontra uma legibilidade possível pelo facto de, na senda de Warburg, "se atrever a fazer... a tentativa de descer às profundidades onde os impulsos do espírito humano se entretecem com a matéria acronologicamente estratificada. Somente ali se descobrem onde se cunharam os valores expressivos dos estremecimentos pagãos derivados da vivência orgiástica original: o thíasos trágico" (Warburg 2010: 4).

Uma cartografia "sintomática" da natureza humana, das suas (/nossas) polaridades e desacertos, seres entre o visceral e o sideral, seres animais que desejam ser deuses, e coisas que só a imaginação, no que esta tem de loucura e de ilusão, nos permite vislumbrar.

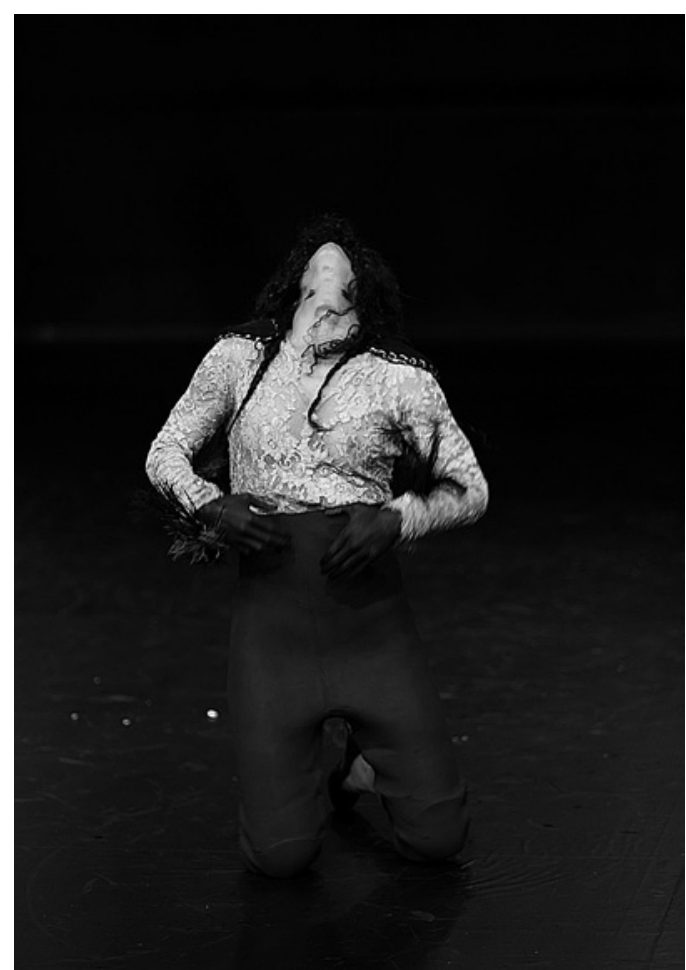

Paraiso - Colecção

Privada,

de Marlene Monteiro

Freitas, Bomba Suicida, 2013

( $<$ Marlene Monteiro Freitas e Andreas Merk;

> Marlene Monteiro) fot. Hervé Véronèse, Centre Pompidou (Cortesia Marlene Monteiro Freitas).

\section{Referências bibliográficas}

AGAMBEN, Giorgio (1999), Potentialities, Stanford, Stanford University Press.

-- (2004), The Open. Man and Animal, Stanford: Stanford University Press, 2004

-- (2007), Infancy and History. On the Destruction of Experience, London, Verso, 2007.

BALONA, Alexandra (2013), Entrevista a Marlene Monteiro Freitas, efectuada por correio electrónico, 23 de Outubro, inédita.

BRANDSTETTER, Gabrielle (1998), Ritual as Scene and Discourse: Art and Science Around 1900 as exemplified by Le Sacre du printemps, The world of music, 40 (I): 37-59.

CALINESCU, Matei (1987), Five Faces of Modernity. Modernism, AvantGarde, Decadence, Kitsch, Postmodernism, Durham, Duke University Press.

DIDI-HUBERMAN, George (2010), Atlas. Cómo llevar el mundo a cuestas? Catálogo Museo Nacional Centro de Arte Reina Sofia, Madrid.

FOUCAULT, Michel (1966), Les mots et les choses. Une archéologie des sciences humaines, Paris, Gallimard.

FREUD, Sigmund (1997), El malestar en la cultura, Madrid, Alianza Editorial. NIETZSCHE, Friedrich (2000), The Birth of Tragedy, Oxford, Oxford University Press.

REISS, Françoise (1958), A vida de Nijinsky, Lisboa, Editorial Estúdios Cor. WARBURG, Aby (2010), Atlas Mnemosyne, Madrid, Akal.

\section{Periódico}

Danser. Les Ballets Russes. Numéro Spécial. Belgique, Hors Série, Décembre 2009.

\section{Sitiografia}

http://cargocollective.com/marlenefreitas/p-a-r-a-i-s-o 